\title{
Simon Kempny
}

\section{Verwaltungskontrolle}

Zur Systematisierung der Mittel zur Sicherung administrativer Rationalität unter besonderer Berücksichtigung der Gerichte und der Rechnungshöfe

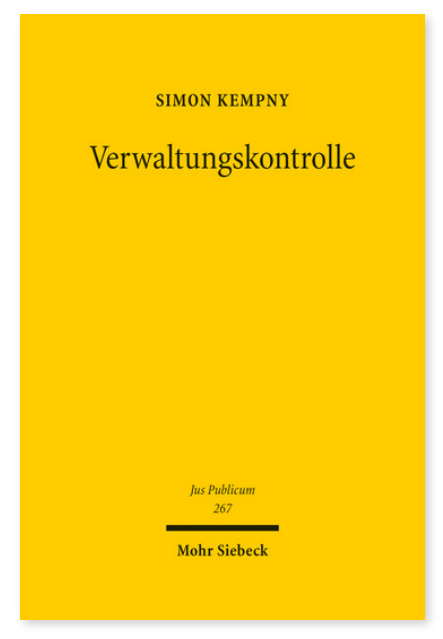

2017. XXIV, 344 Seiten. JusPubl 267

ISBN 978-3-16-155240-3

DOI 10.1628/978-3-16-155240-3

eBook PDF 104,00€

ISBN 978-3-16-154945-8

Leinen $104,00 €$
So gegenwärtig der Begriff der Kontrolle in der rechts- und verwaltungswissenschaftlichen Diskussion ist, so unscharf sind seine Konturen. Definitionen unterbleiben nicht selten, gerade auch unter Hinweis auf die Vielgestaltigkeit des

Vorgefundenen. Simon Kempny unternimmt es, die Kontrolle der Verwaltung in der Bundesrepublik Deutschland und in der Europäischen Union, wie sie durch Gerichte, Rechnungshöfe, verschiedene Beauftragte und weitere Stellen wahrgenommen wird, auf der Grundlage eines Satzes scharf definierter Begriffe systematisierend zu erfassen. Jeweils unter einer von sieben Leitfragen wird zunächst der rechtstheoretische Zusammenhang ausgeleuchtet, sodann der Rechtsstoff dogmatisch aufgearbeitet und schließlich unter verwaltungswissenschaftlichem Blickwinkel gezeigt, inwieweit Kontrolle zur Herstellung und Sicherung administrativer Rationalität beitragen kann.

Simon Kempny ist Professor für Öffentliches Recht und Steuerrecht an der Universität Bielefeld. https://orcid.org/0000-0002-4905-9922
Jetzt bestellen:

https://mohrsiebeck.com/buch/verwaltungskontrolle-9783161552403?no_cache=1

order@mohrsiebeck.com

Telefon: +49 (0)7071-923-17

Telefax: +49 (0)7071-51104 